\title{
Complex reagents for the removal and inhibition of paraffin deposition for highly paraffinic oil production and transportation
}

\author{
S. Askarova ${ }^{1}$, G. Boyko ${ }^{1}$, N. Lyubchenko ${ }^{2}$, R. Sarmurzina ${ }^{3}$ \\ \& U. Karabalin ${ }^{4}$ \\ ${ }^{1}$ Kazakh National Technical University Named After K. I. Satpayev, \\ Kazakhstan \\ ${ }^{2}$ Unat University, Kazakhstan \\ ${ }^{3}$ National company KazMunayGaz, Kazakhstan \\ ${ }^{4}$ KazEnergy, Kazakhstan
}

\begin{abstract}
The chemical-radiation modification of atactic polypropylene can create a new chemical reagent of complex action OAPP-V/200.

The structure and phase composition of the reagent was proved by using IR-spectroscopy and X-ray analysis. It was determined that the reagent has a high degree of amorphization $-65 \%$.

On the basis of this reagent, we created a new composition for inhibiting the dissolution of paraffin deposition. As a solvent, a mixture of aromatic and unsaturated hydrocarbons were used.

The paraffin deposition inhibiting ability of the reagent was tested on the highly paraffinic oil of fields Kumkol and Akshabulak. It was revealed that the inhibition efficiency of the reagent may reach up to $80 \%$. It was also was found that the solvent compound of composition is influenced by inhibition efficiency; it increases with a rise in unsaturated hydrocarbon molecular mass.

The composite mixture based on OAPP-V/200 was tested as a solvent for paraffin deposition at the Kumkol oil field. The results demonstrated that the composition with the highest content of unsaturated hydrocarbons proved to have the best solubility. Under stationary conditions of the experiment, at low temperatures, paraffin deposition dissolution efficiency reached above $70 \%$ within 6 hours.
\end{abstract}


The results of this research show that the unsaturated solvents have good penetration in formed paraffin deposition, contributing to their destruction. Keywords: paraffin deposition, inhibitors and solvents of paraffin deposition.

\section{Introduction}

With the transition to new development stages of oil fields, there has recently been a steady trend towards an increase in the production and transportation of highly paraffinic oil. This kind of oil has a high pour point and abnormal rheological properties, and is prone to paraffin deposition formation in the inner surface of pipes, tanks and other equipment. Currently different countries are conducting active research into increasing the efficiency of managing the problems associated with paraffin deposition [1-4].

Many Kazakhstan oil fields are characterized as having a high content of paraffin. These compounds cause complication in wells and equipment. According to this, investigations in this direction are necessary and relevant.

Chemical methods are widely used in the struggle against paraffin deposition. Reagents in these processes can be categorized into two groups. The appointment of the first group is to remove deposition from the pipes and equipment surfaces. The second direction is preventing paraffin deposition by using chemical reagents, acting on base adsorption processes.

The choice of reagent is based on a thorough study of crude properties, and its behavior in well and surface equipment. Knowledge of paraffin deposition composition and properties allows for the choice of an optimal compound for deposits removal. The composition of paraffin deposits in Kumkol and Akshabulak is presented in Table 1.

Table 1: Composition of paraffin deposits at Kumkol and Akshabulak fields.

\begin{tabular}{|c|c|c|c|c|c|}
\hline \multirow[t]{2}{*}{ Oil field } & \multirow{2}{*}{$\begin{array}{l}\text { Melting } \\
\text { point } \\
\left({ }^{\circ} \mathrm{C}\right)\end{array}$} & \multicolumn{3}{|c|}{ Composition, \% } & \multirow{2}{*}{$\begin{array}{l}\text { Type of } \\
\text { paraffin } \\
\text { deposition }\end{array}$} \\
\hline & & Paraffin & Asphaltene & Resin & \\
\hline Kumkol & 41 & 39.20 & 0.02 & 8.26 & Paraffinic \\
\hline Akshabulak & 40 & 48.50 & 0.01 & 7.04 & Paraffinic \\
\hline \multicolumn{6}{|c|}{$\begin{array}{c}\text { Pour point: } \\
\text { crude Kumkol }+9^{\circ} \mathrm{C} \\
\text { ude Akshabulak }+21^{\circ} \mathrm{C}\end{array}$} \\
\hline
\end{tabular}

Table 1 shows that the studied paraffin depositions significantly differ in paraffin content. The greatest amount of paraffin is found in Akshabulak field's deposition.

The type of paraffin depositions at the Kumkol and Akshabulak fields was determined according to the formula; $\mathrm{P} /(\mathrm{A}+\mathrm{R})$ [5], and there are deposits that can be classified as waxy. 


\section{The main part}

In this work, a new composite structure of complex action with an OAPP-V/200 reagent as the active ingredient in a mixture of unsaturated and aromatic solvents was developed. O-xylene has been investigated as an aromatic hydrocarbon and hexene and octene - unsaturated. OAPP-V/200 was obtained by chemical irradiation of atactic polypropylene. As a source of radiation, the medium energy electron accelerator ELV-4 was used, and the irradiation dose was 200 kGray.

The structure and phase composition of the reagent was studied by using IRspectroscopy and X-ray.

The composition, based on OAPP-V/200, was tested as an inhibitor and solvent of paraffin deposition, and also as a pour point depressant. The OAPP-V/200 concentration in binary solvents was $2.6 \%$.

The objects of study were the Kumkol and Akshabulak fields' highly paraffinic oil and paraffin depositions.

\subsection{Studying the structure and phase composition of OAPP-V/200}

The structure of the obtained reagent was analyzed by IR spectroscopy. IR spectrum was recorded on a spectrometer "Spectrum 65" Perkin Elmer firm.

Figure 1 shows the IR spectrum of OAPP-V/200.

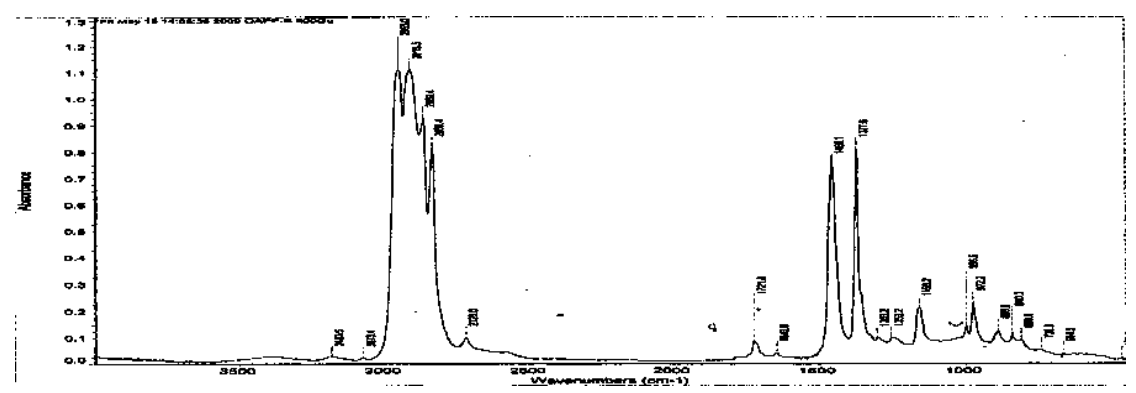

Figure 1: IR-spectrum of OAPP-V/200.

The explanation of the characteristic IR spectrum absorption bands of polymer was conducted in accordance with reference [6].

This data shows the presence of polar functional groups of alcohols, ketenes etc. in macromolecule structure. The presence of large amounts of aliphatic structures was confirmed by an intense absorption in the deformation vibration region of antisymmetric $\mathrm{CH}_{3}$-groups $\left(2955 \mathrm{~cm}^{-1}\right.$ and $\left.1460 \mathrm{~cm}^{-1}\right)$ and the $\mathrm{CH}_{2}$ groups $\left(2915 \mathrm{~cm}^{-1}\right)$, and deformation vibration of symmetric $\mathrm{CH}_{3}$-groups (2869 $\left.\mathrm{cm}^{-1}, 1377 \mathrm{~cm}^{-1}\right)$. The $1721 \mathrm{~cm}^{-1}$ region is equal to the stretching vibrations characteristic of aliphatic ketene, the absorption region $1158 \mathrm{~cm}^{-1}$ is related to the $\mathrm{C}-\mathrm{O}$ stretching vibrations of tertiary alcohols. Also absorption in the region of 972-997 $\mathrm{cm}^{-1}$ is characterized by the presence of vinyl double bonds $-\mathrm{CH}=\mathrm{CH}_{2}$; and the $841-889 \mathrm{~cm}^{-1}$ region by the presence of vinylidene double bonds $\mathrm{CR}=\mathrm{CH}_{2}$. 
The structure and phase composition of the reagent was studied using X-ray. Analysis was conducted using an X-Ray diffractometer X'PertPRO (Holland). The analytical processing of the diffractogram was performed by the X'Pert HighScore PANalytical program. The diffractogram fragment of the sample in the $\mathrm{X}$-ray diffraction angle range from 10 to $30^{\circ}$ is shown in Figure 2.

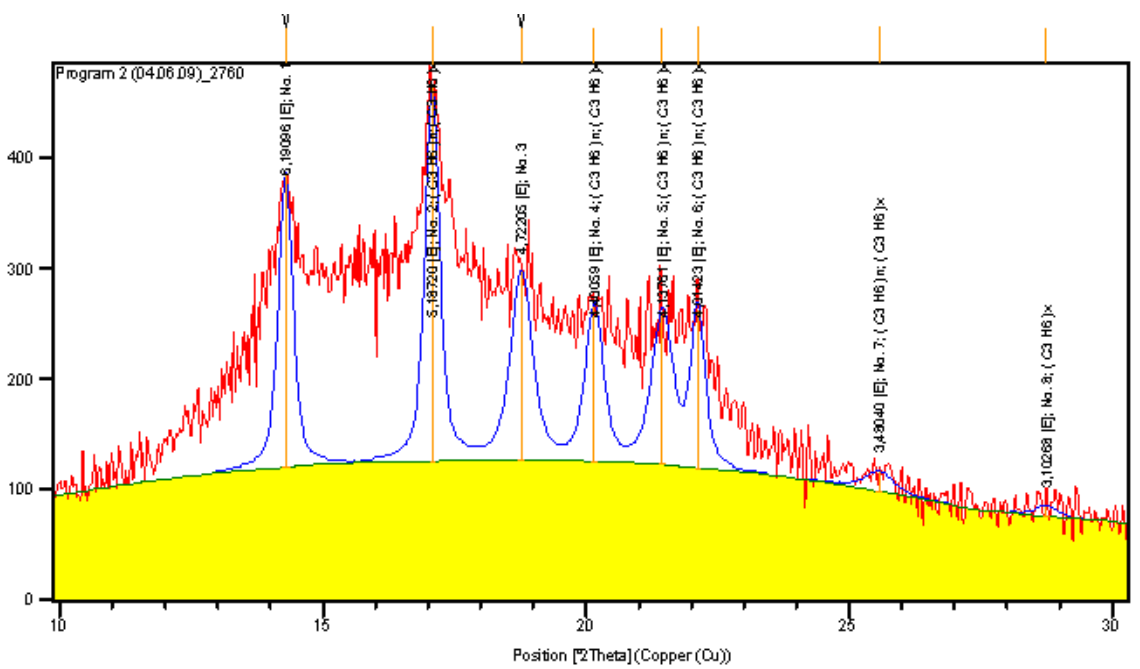

Figure 2: Diffractogram fragment of sample OAPP-V/200 at angles [ ${ }^{\circ} 2$ Theta] from 10 to $30^{\circ}$.

Figure 2 shows high, narrow diffraction peaks, which indicate the presence of crystalline phases in the investigated sample. The roentgenogram of the amorphous component has characteristic type - a broad line (halo), and the angular width of $2 \theta=10-30^{\circ}$. Based on the interplanar spacing size for these identified peaks we can determine that they belong to polypropylene.

During a structural analysis, the degree of sample crystallinity was estimated. The determination of amorphous and crystalline components was made by calculating the squares sum of the angular intervals from 10 to $30^{\circ}$ diffraction reflections. As a result, the data revealed that the reagent amorphous component was $65 \%$. The high degree of amorphization indicates presence in the structure of a large number of polymer molecules packed randomly [7].

\subsection{Assessment of paraffin deposition inhibitors efficiency}

The paraffin deposition inhibition efficiency OAPP-V/200 was tested on cold finger apparatus with thermostatic baths from firm Julabo (Germany).

A $500 \mathrm{ml}$ volume cylindrical stainless steel beaker was filled with $300 \mathrm{ml}$ of oil at room temperature and thermostated up to $30^{\circ} \mathrm{C}$ under magnetic stirring. After 
15 minutes the cooled cold finger was immersed into a beaker made from stainless steel, where a constant temperature of $5^{\circ} \mathrm{C}$ was maintained. The experiments were carried out for 3 hours. Then, the cold finger was taken from the beaker and paraffin deposition was removed mechanically, which is then weighed.

The paraffin deposition percentage was calculated relative to the sample without oil additives. The weight of paraffin deposits in the initial sample was taken as $100 \%$.

The OAPP-V/200 reagent's inhibitory activity in a binary solvents mixture (1:1) from the oil fields of Kumkol and Akshabulak is presented in Table 2. The amount of inhibitor in the composition was $300 \mathrm{ppm}$.

Table 2: Evaluation of the effect of inhibitors.

\begin{tabular}{|c|c|c|}
\hline \multirow{2}{*}{ Oil fields } & \multicolumn{2}{|c|}{ Inhibition efficiency, \% } \\
\cline { 2 - 3 } & $\begin{array}{c}\text { OAPP-V/200 } \\
\text { (hexene:o-xylene) }\end{array}$ & $\begin{array}{c}\text { OAPP-V/200 } \\
\text { (octene:o-xylene) }\end{array}$ \\
\hline Kumkol & 70.0 & 71.3 \\
\hline Akshabulak & 67.8 & 81.0 \\
\hline
\end{tabular}

The analysis of this table shows that the inhibition efficiency depends on the composition. It was revealed that increasing the molecular weight of the unsaturated hydrocarbon increases the inhibitory ability of the composition. For the Akshabulak oil field, this factor rose from $67.8 \%$ to $81 \%$. For the Kumkol oil field, changing the composition of the hydrocarbon slightly affects inhibitory ability.

Thus, the results obtained from these studies demonstrate the strong inhibitory activity of the composition.

\subsection{Studying depressant activity of reagent}

High-molecular paraffins are a determining factor of oil freezing; they develop a spatial structure in macrocrystalline form. The loss of strength is caused by the formation of oil's smallest crystal grid, which binds the liquid portion. The application of the physical methods of influence is used, as well as additives, to reduce the pour point of the oil based on the management of processes of structuring in transition from freely dispersed systems to bond dispersion [8].

Research on the influence that developed composite compositions have on the low temperature properties of Akshabulak oil was performed according to ASTM D 5853-95 (Table 3).

From the analysis of Table 3 it follows that the depressant activity OAPP$\mathrm{V} / 200$ depends on its concentration and also on the nature of binary solvents.

In a solvent system octene:o-xylene the greatest depression at $12^{\circ} \mathrm{C}$ shows that the reagent OAPP-V/200 has a concentration of $300 \mathrm{ppm}$.

The pour point Akshabulak oil reaches $12^{\circ} \mathrm{C}\left(\right.$ depression $\left.9^{\circ} \mathrm{C}\right)$ at a concentration of $100 \mathrm{ppm}$ in the solvent system hexene:o-xylene. 
Table 3: Thermo-chemical treatment results of Akshabulak crude oil with different compositions at $60^{\circ} \mathrm{C}$.

\begin{tabular}{|c|c|c|c|c|}
\hline Depressant & $\begin{array}{c}\text { Amount of } \\
\text { depressant, } \\
\text { ppm }\end{array}$ & $\begin{array}{c}\text { Binary solvent } \\
\text { system }\end{array}$ & $\begin{array}{c}\text { Treated oil } \\
\text { pour point, } \\
{ }^{\circ} \mathrm{C}\end{array}$ & $\begin{array}{c}\text { Depression, } \\
{ }^{\circ} \mathrm{C}\end{array}$ \\
\hline \multirow{2}{*}{$\begin{array}{c}\text { OAPP- } \\
\text { V/200 }\end{array}$} & 100 & Hexene:o-xylene & +12 & 9 \\
\cline { 2 - 5 } & \multirow{2}{*}{200} & Octene:o-xylene & +15 & 6 \\
\cline { 2 - 5 } & \multirow{2}{*}{300} & Hexene:o-xylene & +21 & 0 \\
\cline { 2 - 5 } & & Octene:o-xylene & +12 & 9 \\
\cline { 2 - 5 } & \multirow{2}{*}{500} & Hexene:o-xylene & +21 & 0 \\
\cline { 2 - 5 } & & Octene:o-xylene & +9 & 0 \\
\cline { 2 - 5 } & Hexene:o-xylene & +21 & 3 \\
\hline
\end{tabular}

\subsection{Estimation of paraffin deposition solvents efficiency}

In this chapter we studied the influence of temperature on the efficiency of the composition solvent's ability of paraffin deposition.

The paraffin deposition (Kumkol field) dissolution process investigation was carried out at temperatures of $10^{\circ} \mathrm{C}$ and $20^{\circ} \mathrm{C}$, according to the Standard Oil Company "Bashneft" [9].

$10 \mathrm{~cm}^{3}$ of the test composite composition was poured into a cylinder and lowered into the cylinder grid with the paraffin deposition. Tests were carried out for 6 hours; every hour the grid with deposition was removed from the cylinder, allowed to drain, and any solvent remaining on the surface and deposition on the grid was weighed on an analytical balance. Throughout the experiment, from time to time the grid is raised and lowered (every 15 minutes) to simulate a wellequipped sucker rod.

Solvent efficiency - E, \%, calculated by the eqn (1):

$$
\mathrm{E}=\frac{m_{0}-m_{n}}{m_{0}} \times 100 \%
$$

here, $\mathrm{m}_{0}-$ deposition mass taken for experiment, $\mathrm{g}$; $\mathrm{m}_{\mathrm{n}}$ - deposition mass after experiment, $\mathrm{g}$.

In Figure 3, the coordinates of dissolution efficiency (E, \%) - time ( $\mathrm{t}, \mathrm{h})$ present the paraffin dissolution and the kinetic curves in various compositions at $10^{\circ} \mathrm{C}$. The curve analysis showed that the paraffin dissolution began from the first hour. This shows the high reactivity of the solvent. For OAPP-V/200 (hexene:o-xylene) paraffin dissolution efficiency in an hour is $42.5 \%$, and for the composition OAPP$\mathrm{V} / 200$ (octene:o-xylene) it is $54.6 \%$. Over time we observed that the process of dissolution efficiency smoothly climbs, and within 6 hours reaches $54.8 \% 74.6 \%$ respectively. 


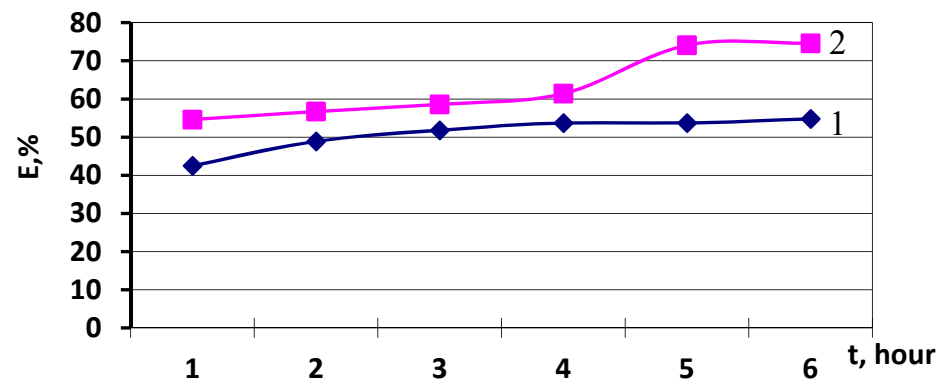

Figure 3: Curves of paraffin deposition dissolution in various times at $10^{\circ} \mathrm{C}$ by using compositions: 1-OAPP-V/200 (hexene:o-xylene), 2-OAPP$\mathrm{V} / 200$ (octene:o-xylene).

Research at the ambient temperature of $20^{\circ} \mathrm{C}$ showed that these compositions totally dissolved paraffin deposition (Table 4), which allows for the use of these composite compounds in the cold season.

Table 4: Results of the destruction efficiency paraffin deposition with different compositions.

\begin{tabular}{|c|c|c|c|}
\hline & $\mathrm{t},{ }^{\circ} \mathrm{C}$ & $\begin{array}{c}\text { OAPP-V/200 } \\
\text { (hexene:o-xylene) }\end{array}$ & $\begin{array}{c}\text { OAPP-V/200 } \\
\text { (octene:o-xylene) }\end{array}$ \\
\hline $\begin{array}{c}\text { Dissolving } \\
\text { efficiency, } \%\end{array}$ & 10 & 54.8 & 74.6 \\
\cline { 2 - 4 } & 20 & 100 & 100 \\
\hline
\end{tabular}

The analysis of the paraffin dissolution process found that, under low temperature conditions, the composition OAPP-V/200 (octene:o-xylene) is recommended.

Thus, a new composite composition was created with an active substance of irradiated atactic polypropylene in a binary solvent system hexene:o-xylene and octene:o-xylene.

It is shown that the use of OAPP-V/200-based composition on Kumkol and Akshabulak crude oil promotes paraffin deposit inhibition, dissolution formed solid deposition and improves the low-temperature properties of highly paraffinic oil.

\section{References}

[1] Zhang F., Ouyang J., Hong L., Feng X. \& Zhang H., Inhibition of deposits of high-molecular weight paraffins in oil wells. Chemistry and Technology of Fuels and Oils, 47(1), pp. 53-57, 2011.

[2] Thanh N., Hsieh M., Allen J. \& Philp R.P., Paraffin and asphaltene deposition resulting from commingling of oils during pipeline transportation and storage. 
Preprints of symposia-division of fuel chemistry American chemical society, 43(2), pp. 213-215, 1998.

[3] Keating J.F. \& Wattenbarger R.A., The simulation of paraffin deposition and removal in wellbores. SPE paper 27871 presented at the Western Regional Meeting held in Long Beach: California, USA, pp. 227-235, 1994.

[4] Bello O.O., Fasesan S.O., Akinyemi O.P, Macaulay S.R.A. \& Latinwo G.K., Study of the influence of xylene-based chemical additive on crude oil flow properties and paraffin deposition inhibition, Engineering journal of University of Qatar, 18, pp. 15-28, 2005.

[5] Akchurin V.A., Marin V.I. \& Demahin A.G., Chemical methods for removing and preventing the formation of paraffin in oil, College: Saratov, p. 22, 2001.

[6] Tarasevich B.N. Fundamentals of infrared Fourier transform spectroscopy. Sample preparation in IR spectroscopy, State University named after Lomonosov: Moscow, p. 222, 2012.

[7] Lee T.H., Boey F.Y.C. \& Khor K.A. X-ray diffraction analysis technique for determining the polymer crystallinity in a polyphenylene sulfide composite, Polymer composites, 16(6), pp. 481-488, 1995.

[8] Mansoori G. Ali, Phase behavior in petroleum fluids, To appear in Encyclopedia of Life Support Systems, UNESCO, 2009. http://www.eolss.net/sample-chapters/c08/E6-185-03.pdf

[9] Standart, The procedure of laboratory and pilot field testing of chemicals for use in the processes of production and processing of oil and gas, ST-17-0302. AOK "Bashneft" from 21.10.2011. 